\title{
Integrated management of groundwater exploitation and recharge in Shanghai based on land subsidence control
}

\author{
Tianliang Yang ${ }^{1,2,3}$, Xuexin Yan ${ }^{1,2,3}$, Xinlei Huang ${ }^{1,2,3}$, and Jianzhong $\mathbf{W u}^{1,2,3}$ \\ ${ }^{1}$ Key Laboratory of Land Subsidence Monitoring and Prevention, \\ Ministry of Natural Resources, Shanghai, China \\ ${ }^{2}$ Shanghai Institute of Geological Survey, Shanghai, China \\ ${ }^{3}$ Shanghai Engineering Research Center of Land Subsidence, Shanghai, China \\ Correspondence: Tianliang Yang (sigs_ytl@ 163.com)
}

Published: 22 April 2020

\begin{abstract}
Shanghai has a long history of exploitation and utilization of groundwater in order to meet the needs of industrial production and residential water. As a result, serious land subsidence disasters were induced. Land subsidence poses a huge security threat to the low-altitude coastal city of Shanghai. The development of land subsidence in Shanghai is closely related to the exploitation of underground water. In order to control land subsidence disasters, Shanghai has taken three key measures, i.e., the amount of compressed groundwater exploitation, the adjustment of groundwater exploitation level, and the implementation of artificial groundwater recharge, which have become the most effective measures for land subsidence control. However, as the groundwater levels of various aquifers in the region rise sharply, land subsidence is effectively controlled, and the measures of groundwater exploitation and recharge need to be dynamically adjusted to adapt to the current situation. In this context, from the perspective of history, the paper analyzes the long-term groundwater exploitation and recharge process and the development characteristics of land subsidence in Shanghai and studies the evolution process of land subsidence in different stages. From the perspective of land subsidence prevention and control, the paper analyzes the management measures of groundwater exploitation and recharge and the great achievements. The research results can provide a basis for land subsidence control and comprehensive groundwater management in the new period and can also provide a demonstration and reference for groundwater resource management in similar areas.
\end{abstract}

\section{Introduction}

Land subsidence is a worldwide geological hazard, which is very significant in plain or basin areas. The main reason is unreasonable exploitation of groundwater (Wei et al., 2009). As a precious natural resource, the scientific and effective management of groundwater is very important, especially for land subsidence control. Since the opening of the port, Shanghai has begun to develop and utilize groundwater resources. While serving production and living, groundwater resources have caused serious land subsidence problems. In order to control land subsidence, Shanghai has carried out groundwater exploitation control and implemented an artificial groundwater recharge project. The innovative dynamic management mechanism of groundwater exploitation and recharge has played an important role in preventing and controlling land subsidence in Shanghai. It has demonstration and reference value.

\section{Overview of land subsidence in Shanghai}

\subsection{History of land subsidence}

The phenomenon of land subsidence was discovered in Shanghai in 1921, which is the earliest city discovered in China. It has experienced the development history of land subsidence for nearly a century, and it is one of the areas with the most serious land subsidence in China. From the perspective of land subsidence development, it can be generally divided into two periods, namely, a serious development 
period of land subsidence (1921-1965) and a land subsidence control period (1966 to present). Since 1966, the monitoring data of land subsidence in the downtown area of Shanghai have shown that, with the change in groundwater exploitation and artificial recharge pattern and urban construction, land subsidence in Shanghai presents a trend of continuous development in time and space. Since the implementation of land subsidence control measures in the 1960s, after more than 50 years of land subsidence monitoring and prevention, land subsidence control has achieved great results (Fig. 1).

\subsection{Development status of land subsidence}

According to the long-term monitoring data of land subsidence, land subsidence decreases year by year in Shanghai. At present, the average annual land subsidence has been controlled within $6 \mathrm{~mm}$ for 10 consecutive years. The settlement funnel area in the city has been greatly reduced, and some areas have seen small ground rebound, but the maximum annual settlement in some areas is about $20 \mathrm{~mm}$. There are still several small settlement funnel areas, so now it can be seen that uneven settlement features are the most prominent.

Due to different sedimentary environments and properties of soil layers, the characteristics of deep and shallow soils are quite different. In a general way, the first confined aquifer and the strata above it are referred to as the "shallow soil layer", and the strata below the first confined aquifer are referred to as the "deep soil layer". With long-term groundwater overexploitation and utilization of underground space, different depths of soil deformation characteristics have also changed dramatically; subsidence of the deep soil layer has not been obvious in recent years. But the shallow soil layers have been influenced by engineering construction and shallow soft soil consolidation, and the proportion of the overall land subsidence is continuing to grow. According to the statistical analysis of the monitoring data of stratified soil settlement from 1980 to 1995 , the proportions of shallow and deep soil subsidence were about $45 \%$ and $55 \%$. From 1990 to 2000, the subsidence of the shallow and deep soil layers accounted for about $40 \%$ and $60 \%$. Since 2000, the cumulative deformation of the shallow soil layer has contributed about $70 \%$ of the total land subsidence. It can be seen that the control of shallow strata subsidence is vitally important to the control of land subsidence, especially in the case of a large reduction of groundwater exploitation. Thus, land subsidence is mainly caused by the settlement of the shallow soil layer, while the deep soil layer even shows the trend of slight rebound.

\section{The relationship between land subsidence and groundwater}

\subsection{Inducing factors of land subsidence}

The influencing factors of land subsidence are very complex, and their development and influence degree vary greatly in spatial and temporal distribution. The fundamental factors are closely related to the buried depth and undulation of the bedrock, the thickness of Quaternary overburden and geological structure characteristics, the development of aquifers and groundwater exploitation, and engineering construction activities.

\subsubsection{Geological environment conditions are the background conditions of land subsidence}

The neotectonic movement formed the basic pre-Quaternary geomorphologic framework of two sedimentary depressions and three sedimentary uplifts. Since the Quaternary period, influenced by marine environments frequently alternating, Quaternary sediments' genetic types have been relatively complex, sand and clay soil layers have appeared alternately, and the soft soil layer has been in development and had an obvious rhythm-changing law. The development of more than four water-rich confined aquifers constitutes the material basis of land subsidence. Therefore, based on the Quaternary geological environment conditions, intense groundwater exploitation activities have caused a number of large subsidence funnels. Holocene soft soil has been consolidated due to engineering activities, so development intensity of land subsidence is relatively large basically in the landsubsidence-prone area (Yang et al., 2010).

\subsubsection{Overexploitation of groundwater is the main external cause of land subsidence}

There are five confined aquifers in the Quaternary strata in Shanghai, which are very water-rich. In the course of economic and social development, as early as 1860 the first deep well in the city center was excavated for use to meet the industrial production and living consumption. Unfortunately, the intensity, volume and spatial distribution of underground water are all in disorder. In the 1960s groundwater extraction peaked at 200 million tons a year, which caused serious land subsidence problems. It can be found that there is a good consistency between land subsidence and groundwater exploitation. Since then, groundwater management measures such as compressed groundwater extraction and artificial recharge have been adopted, and land subsidence has been under control (Fig. 2). Nevertheless, unreasonable groundwater exploitation was still the main influencing factor in land subsidence (Yang et al., 2014). 


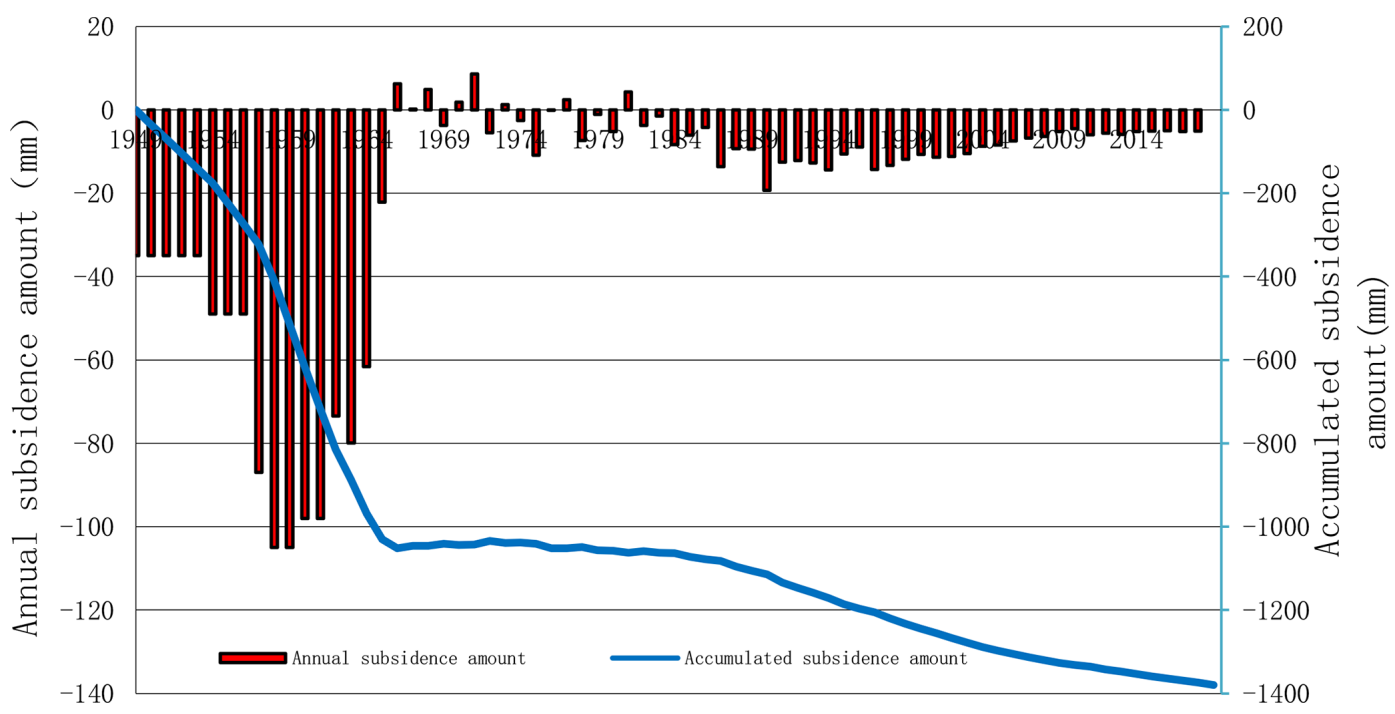

Figure 1. Land subsidence development duration characteristic curve in Shanghai.

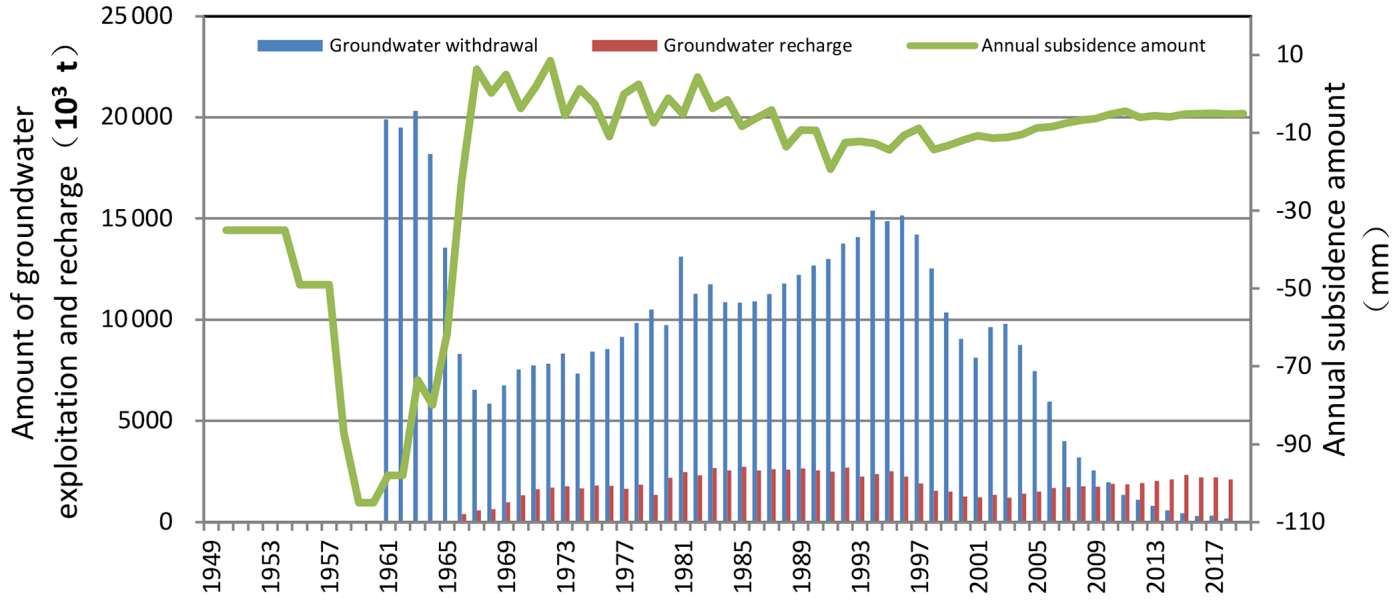

Figure 2. Historical graph of annual groundwater intake and land subsidence in Shanghai.

\subsubsection{Construction activities have become an important cause of land subsidence}

Since ground subsidence has been under control, the annual average subsidence was reversed from the maximum of $105 \mathrm{~mm}$ to a small rebound, and the land subsidence rate was effectively controlled. In recent years, with the significant compression of groundwater exploitation and steady increase in groundwater recharge, the groundwater level has been raised to a higher level, but land subsidence is still developing continuously. Especially from the 1990s to the beginning of this century, the land subsidence rate had an increasing trend. Since the beginning of this century, the rate of land subsidence has been further controlled but has still continued to develop. Through long-term area leveling and soil stratification settlement monitoring, it is found that there are many settlement centers in the region with small scope, wide distribution and different development degrees, and land subsidence presents prominent uneven characteristics. The compression deformation of the shallow soft soil layer and the water-bearing sand layer affected by engineering construction activities has become an important factor in land subsidence (Yang, 2012; Yan et al., 2019).

\subsection{Dynamics of groundwater exploitation and recharge}

As demand for groundwater resources changes constantly, the utilization of groundwater also changes correspondingly. Meanwhile, in order to control land subsidence, artificial groundwater recharge was implemented for a long time. Before the 1960s, groundwater exploitation was mainly concentrated in the second and third artesian aquifers in the middle and shallow areas, accounting for more than $80 \%$ of the total exploitation volume. Artificial groundwater recharge has 
been implemented since 1966, and the aquifer and quantity of groundwater recharge have been gradually adjusted. In the early stage, it mainly recharges the second and third confined aquifers. And in the middle stage, it mainly recharges the second, third and fourth aquifers. However, in the recent period, it recharges the second, third, fourth and fifth aquifers. In general, the annual exploitation and recharge volume of groundwater have shown a trend of decreasing and increasing year by year. The annual exploitation volume has decreased from nearly 200 million tons at the highest level to less than 10 million tons at present. And the annual recharge volume has increased from 3.9 million tons in the early stage to about 21 million tons at present. It can be seen that at present, the amount of groundwater exploitation and recharge in the city has undergone a huge reversal. It has gone through the stages of imbalance of exploitation and recharge and balance of exploitation and recharge, and recharge is much greater than exploitation.

\subsection{Correlation between land subsidence and groundwater}

The long-term monitoring of land subsidence and groundwater level shows that the unreasonable exploitation of groundwater breaks the balance of groundwater flow field and stress field. And this directly influences the development and distribution of land subsidence. In the early 1960s, when the exploitation reached its peak, the annual land subsidence reached its maximum of $105 \mathrm{~mm}$. Since 1966, as a result of groundwater control measures, land subsidence has quickly slowed down, and there has even been a partial rebound. The groundwater level of each aquifer has been continuously rising for many years, and land subsidence has also maintained a relatively stable amount: the average annual land subsidence especially in the last 10 years has been controlled within $6 \mathrm{~mm}$. It can be seen that groundwater exploitation has a direct impact on the occurrence and development of land subsidence. Therefore, unreasonable exploitation of groundwater is the key factor leading to land subsidence.

\section{Integrated groundwater management based on land subsidence control}

\subsection{Compressed groundwater exploitation}

Since Shanghai opened its port in 1860, groundwater has been used for production and living for a long time. From 1860 to 1921 , there were only 22 deep wells with an annual exploitation volume of about 500000 tons in the city. By 1933, however, there were 392 deep wells with an annual exploitation capacity of 13.87 million tons. By 1949, the number of deep wells had increased to 708, with an annual exploitation volume of 87.5 million tons. With the rapid development of industrial production, the amount of groundwater exploitation and the number of wells increased simul- taneously and reached a peak of about 200 million tons in 1963. This is mainly concentrated in the old urban area of the center, and the exploitation wells mainly exploit the second and third confined aquifers in the shallow layers. They can be used as a cooling water source for the textile, smelting and other industries and as a supplementary water source for daily life. Among them, the groundwater in this stage is mainly industrial water, accounting for about $80 \%$ of the total exploitation.

Overexploitation of groundwater has led to serious land subsidence, which directly threatens urban safety. From 1965, the city began to regulate and control the amount of groundwater exploitation wells and restrict the amount of groundwater exploitation. As a result, the total number of exploitation wells has been reduced, and the amount of groundwater exploitation has been greatly reduced, basically remaining at about 75 million tons annually. The land subsidence has been effectively alleviated. However, in the 1980s and 1990s, with the influence of urban development and engineering construction activities, the amount of groundwater was increased to 150 million tons annually. The land subsidence rate also tended to accelerate. Since 2000, with the adjustment of urban industrial structures and the reform of water supply integration, the amount of groundwater and the number of deep wells have been reduced sharply. Shanghai has bid farewell to the "era of deep wells". Now the groundwater levels of all confined aquifers continue to rise. Land subsidence continues to decrease.

\subsection{Adjust aquifers of groundwater exploitation}

In view of the serious land subsidence problem, in order to better coordinate the relationship between land subsidence control and urban development, the main exploitation aquifers have been gradually adjusted from shallow to deep aquifers since 1965. The amount of exploitation and the number of single wells have been generally reduced. In practice, the number of wells in the second and third confined aquifers has decreased significantly, and it is spreading from downtown to the suburbs. The number of wells in the fourth and fifth confined aquifers has gradually increased. This has effectively slowed the subsidence of the aquifer.

\subsection{Implement artificial groundwater recharge}

In order to control land subsidence, artificial groundwater recharge was officially started in 1966. From 1966 to 1981, the amount of groundwater recharge increased year by year, from about 3.8 million tons to about 24 million tons. The ratio of groundwater recharge to extraction is $0.05-0.29$. Groundwater management adopts winter recharge and summer use. With the strengthening of deep well management, a series of measures such as groundwater exploitation and a recharge plan were implemented. The amount of groundwater extracted continues to decrease, and the amount of 
recharge is steadily increasing and remains at the level of 20 million tons. At present, the state of recharge is much larger than the amount of exploitation. On the whole, the groundwater exploitation is characterized by the development from unordered exploitation to orderly exploitation, which is greatly affected by the development level and industrial adjustment in different periods. The level of each confined aquifer continues to rise, and land subsidence is effectively controlled. However, groundwater recharge management is still extensive; a recharge well layout is not reasonable, and aquifers of recharge are not fine enough.

\subsection{Control of shallow engineering dewatering}

Groundwater resources are abundant in Shanghai. The level of phreatic water is only $0.5 \mathrm{~m}$. The pressure of the artesian head is large, which is dangerous for underground space development. Thus, underground engineering construction must carry out engineering dewatering activities. The safety of foundation pit engineering can be guaranteed by pumping groundwater in the shallow soil layer and lowering the confined head. However, this will lead to serious land settlement problems, especially significant uneven settlement.

Tianliang Yang and other experts have made a number of innovative achievements in the research and demonstration application of ground settlement control caused by dewatering in deep foundation pit engineering. On the basis of analyzing the law of land subsidence, they put forward the control index of land subsidence caused by dewatering in deep foundation pit engineering and established the dual control index system of land subsidence and groundwater level. From the perspective of long-term land subsidence characteristics, the key to controlling land subsidence caused by dewatering in deep foundation pit engineering mainly lies in controlling the excessive depth drop in the underground water level outside the pit.

\subsection{Law and regulations for groundwater management}

Due to the unreasonable exploitation of groundwater and engineering dewatering activities, serious land subsidence is caused. Therefore, the control of groundwater activities has become the main measure of land subsidence control. Since the 1970s, Shanghai has introduced a number of groundwater management regulations to control groundwater exploitation and manage artificial groundwater recharge. In 2013, the Shanghai municipal regulations on the prevention and control of land subsidence were officially issued, defining the government's responsibilities for the prevention and control of land subsidence. The law became the first local law on land subsidence control in China. The linkage working mechanism of land subsidence prevention and control by multiple government departments was established. This has become the basis for the long-term monitoring and preven- tion of land subsidence and provided the basic guarantee for urban safety and disaster prevention and reduction.

\section{Conclusion and suggestion}

1. The occurrence and development of land subsidence are always closely related to the exploitation and utilization of groundwater. Therefore, the key measure to prevent land subsidence is the control of groundwater exploitation and utilization.

2. The control of land subsidence must start from the control of groundwater, which can be achieved by taking comprehensive measures such as reducing the exploitation amount, adjusting the aquifers of groundwater exploitation, implementing artificial recharge of groundwater and supervising engineering dewatering activities.

3. In general, a comprehensive land settlement prevention and control system should be established. The technical measures of land subsidence control are the important foundation. Laws and regulations are important safeguards to effectively control land subsidence. The coordinated control mechanism of land subsidence is the key.

Data availability. The data used in this study are available from Shanghai information sharing platform for geological data.

Author contributions. The author made a comprehensive analysis and wrote the paper, and the co-authors collected and collated the data and participated in the writing of parts of the paper.

Competing interests. The authors declare that they have no conflict of interest.

Special issue statement. This article is part of the special issue "TISOLS: the Tenth International Symposium On Land Subsidence - living with subsidence". It is a result of the Tenth International Symposium on Land Subsidence, Delft, the Netherlands, 17-21 May 2021.

Acknowledgements. This work was supported by the Science and Technology Commission of Shanghai Municipality (18DZ1201101) and the International Geoscience Programme (IGCP), project no. 663 (IM2LSC).

Financial support. This research has been supported by the Science and Technology Commission of Shanghai Municipality (grant no. 18DZ1201101) and the International Geoscience Programme (IGCP), project no. 663 (IM2LSC) (grant no. IGCP 663). 


\section{References}

Wei, Z. X., Wang, H.M., Wu, J. Z., Fang, Z. L., and Liu, G. B.: Land subsidence and its influences on urban security of Shanghai, Shanghai Geology, 30, 34-39, 2009.

Yan, X. X., Yang, T. L., Lin, J. X., Huang, X. L., and Wang, J. $\mathrm{X}$. Influence factors analysis and calculation of land subsidence caused by dewatering of ultra-deep foundation pit, Journal of Nanjing University (Natural Science), 55, 401-408, 2019.
Yang, T. L.: Analysis of the Land Subsidence Impact of Dewatering of Deep Foundation Pits, Shanghai Land Resour., 33, 41-44, 2012.

Yang, T. L. and Gong, S. L.: Microscopic analysis of the engineering geologic behavior of soft clay in Shanghai, China, B. Eng. Geol. Environ., 69, 607-615, 2010.

Yang, T. L., Wang, H. M., and Jiao, X.: Land subsidence zoning control in Shanghai, Shanghai Geology, 35, 105-109, 2014. 